\title{
Smart phone assisted detection and quantification of cyanide in drinking water by paper based sensing platform
}

\author{
Anıl İncel ${ }^{\mathrm{a}}$, Osman Akın ${ }^{\mathrm{b}}$, Ali Çağır ${ }^{\mathrm{c}}$, Ümit Hakan Yıldız ${ }^{\mathrm{c}, *}$, Mustafa M. Demir ${ }^{\mathrm{a}}$ \\ a Department of Material Science and Engineering Izmir Institute of Technology, Urla, 35430, Izmir, Turkey \\ b Department of Mechatronics, İzmir Katip Çelebi University, Çiğli, İzmir, Turkey \\ ${ }^{\mathrm{c}}$ Department of Chemistry, Izmir Institute of Technology, Urla, 35430, Izmir, Turkey
}

\section{A R T I C L E I N F O}

\section{Article history:}

Received 17 January 2017

Received in revised form 27 May 2017

Accepted 30 May 2017

Available online 10 June 2017

\section{Keywords:}

Smart phone cyanide detector

Paper based sensing platform

Naked eye detection

Fluorescence turn on assay

\begin{abstract}
A B S T R A C T
An organometallic dye, europium tetrakis dibenzoylmethide triethylammonium (EuD 4 TEA) and gold nanoparticles (Au NPs) impregnated paper based sensor platform have been utilized for development of fluorescence turn-on cyanide assay in aqueous media. The ordinary filter paper with $6 \mu \mathrm{m}$ pore size were employed as solid support that facilitates impregnation of EuD 4 TEA and gold nanoparticles and provides durability. Detection mechanism relying on two processes (i) dissolution of gold nanoparticles causing fluorescence recovery and (ii) ligand exchange of triethyl amine with $\mathrm{CN}$ group stimulating cyanide specific fluorescence enhancement. The paper platform exhibit naked eye distinguishable color transition upon $\mathrm{CN}^{-}$addition from $10^{-2}$ to $10^{-12} \mathrm{M}$. To standardize the methodology a homemade image processing algorithm has been developed that enabling calibration of color change and quantify $\mathrm{CN}^{-}$concentration. The described algorithm is applicable to Android smart phones and facilitate transforming these devices into a quantitative cyanide detector. The overall methodology provides instrument free cyanide detection and therefore rapid control of water quality and safety at off-field conditions.
\end{abstract}

(c) 2017 Elsevier B.V. All rights reserved.

\section{Introduction}

Cyanide is heavily used in common processes of plastic manufacturing, electroplating, and mining industry that results over million tons of global demand per annum increasing the risk of contamination of ground water [1-4]. The continuous monitoring cyanide level of ground water is therefore crucial at close proximity of industry-connected risk areas (the lethal dose of the cyanide in drinking water $1.9 \mu \mathrm{M}$, [4]). Optical reporters are of interest due to capability for rapid and accurate cyanide sensing in aqueous media, and their significance on sensing given in comprehensive reviews $[5,6]$. The number of studies, have also described new cyanide receptors such as an acylhydrazone [7], gluco-conjugated $o$-(carboxamido) aldehyde hydrazine linked azo dye [8], 4,4'-bis-[3-(4-nitrophenyl) thiourea] diphenyl methane (or ether) [9], dual-modal probes based on coumarin and a malonyl urea derivatives dyes [10], aggregation-induced emissive hexaphenylbenzene [11], 7,7,8,8-tetracyanoquinodimethane [12],

\footnotetext{
* Corresponding author.

E-mail address: hakanyildiz@iyte.edu.tr (Ü.H. Yıldız).
}

and near-infrared chemodosimeters based on 5,10-dihexyl-5,10dihydrophenazine [13]. These and other alternatives [14-19] have been utilized as selective and sensitive color change or fluorescence turn-on based detection of cyanide in aqueous media. Although number of assays [20-26] are available for cyanide detection in aqueous media, the most of them require laboratory, instruments, skilled technicians and long detection period. The translation of current cyanide assay methodologies to naked-eye-detection kit is challenge and the need for rapid, accurate, cost-effective detection still unmet. The combination of two technologies paper based sensing and smart phone hold great promise to overcome major difficulties of current methodologies and exhibit a potential to provide naked eye detection of cyanide. The paper based sensing platforms, acts as a novel alternative to the lab-based instrument dependent detection methods since they have several advantages such as simplicity, portability, cost effectiveness, and disposability [27-29]. The paper based sensors have been utilized raging from clinical diagnoses to food quality control, and environmental monitoring [30-33]. On the other hand, recent advances in mobile communication, smart phone technology as well as user friendly software (applications) enable developing of alternative sensing strategies [34-40]. Here we present a new fluorescence turn on cyanide 
detection assay employs disposable paper based sensing platform and mobile application that provide detection and quantification of cyanide in aqueous media. An organometallic dye, europium tetrakis dibenzoylmethide triethylammonium (EuD 4 TEA) impregnated filter paper test platform used for specific detection of cyanide $\left(\mathrm{CN}^{-}\right)$. The proposed methodology facilitate dye-paper impregnation with simple fabrication steps that minimize the variations. To provide naked eye detection gold nanoparticles have also been employed to control quenching and recovery. Upon reaction with $\mathrm{CN}^{-}$the synergetic effect of fluorescence recovery and enhancement by $\mathrm{EuD}_{4}$ TEA-Au NPs paper sensor causes naked eye distinguishable color change. This report also describes facilitation of quantitative detection of $\mathrm{CN}^{-}$by custom-made image processing algorithm to standardize the detection methodology which recognize color codes providing $\mathrm{CN}^{-}$detection as low as $10^{-12} \mathrm{M}$. The new algorithm is applicable to ordinary smart phone equipped with camera and transforms these devices in to a quantitative cyanide detector.

\section{Experimental section}

\subsection{Materials and methods}

Europium (III) nitrate pentahydrate (99.9\% trace metal basis), 1,3,-diphenyl-1,3-propanedione (99.8\%), triethylamine ( $\geq 99.0 \%)$, Gold(III) chloride hydrate $\left(\mathrm{HAuCl}_{4} \cdot \mathrm{xH}_{2} \mathrm{O}\right)(99.9 \%$ trace metal basis), sodium citrate tribasic dihydrate $\left(\mathrm{Na}_{3} \mathrm{C}_{6} \mathrm{H}_{5} \mathrm{O}_{7}\right)(\geq 99.0 \%)$, and each salt were purchased from Aldrich. The ordinary filter paper (Whatman 1003-320 grade 3) made of Cellulose with $6 \mu \mathrm{m}$ pore size were used. All other reagents and solvents were commercially available at analytical grade and were purified for preparing solutions. ${ }^{1} \mathrm{H}$ NMR spectra were recorded on a Varian $400 \mathrm{MHz}$ spectrometer at $400 \mathrm{MHz}$. UV-vis spectra were recorded on a Varian Cary 50 UV-vis spectrophotometer. Fluorescence spectra were obtained on a Varian Cary Fluorescence spectrometer, excitation was $365 \mathrm{~nm}$. FTIR spectra were taken Perkin Elmer Fourier Transform Infrared Spectroscopy when the range from $400 \mathrm{~cm}-1$ to $4000 \mathrm{~cm}-1$. Microscopy images were taken from Olympus IX2ILL100 Fluorescence Microscopy and Philips XL-30S FEG Scanning Electron Microscopy.

\subsection{Synthesis of europium tetrakis (Dibenzoylmethide) triethylammonium $\left(E_{4} D_{4} T E A\right)$}

The synthesis of $\mathrm{EuD}_{4} \mathrm{TEA}$ [41] was started to dissolve $13 \mathrm{mmol}$ of 1,3-Diphenyl-1,3-propanedione (DBM) in $50 \mathrm{~mL}$ of anhydrous ethyl alcohol under heating at $100^{\circ} \mathrm{C}$. After complete dissolution, $14 \mathrm{mmol}$ of triethylamine (TEA) was added into the hot solution. Separately, $4 \mathrm{mmol}$ of europium (III) nitrate hexahydrate was dissolved in $25 \mathrm{~mL}$ of anhydrous warm ethyl alcohol and the solution was sonicated for 2 min using an ultrasonic bath. The europium salt solution was then added to the DBM and TEA solution. The reaction was stirred and heated at $200^{\circ} \mathrm{C}$ for $1 \mathrm{~h}$ under controlled conditions. During this period, the solution became clear. The solution was then kept aside to cool to room temperature. The formed crystal particles were filtered by using vacuum filtration followed by rinsing the crystals with pure ethyl alcohol and then dried in air. Finally, fluorescent yellow particles were obtained.

\subsection{Synthesis of gold nanoparticles (Au NPS)}

In a typical synthesis [42], $\mathrm{HAuCl}_{4}$ solution $(0.5 \mathrm{mM})$ in water was heated at $80^{\circ} \mathrm{C}$ and the reducing agent, trisodium citrate solution $(38.8 \mathrm{mM})$ was added the chloroauric acid solution. The solution was kept boiling until color change to red, and then the heat was immediately removed. The uniformly dispersed gold nanoparticles were obtained with the particle size as $30 \mathrm{~nm}$ and Absorption spectra of Au NPs showed a classical peak centered at $525 \mathrm{~nm}$.

\subsection{Sensitivity and selectivity measurement}

The fluorescent-dye solution was prepared by dissolving EuD $_{4}$ TEA in N,N-Dimethyl formamide (DMF) and the concentration of main solution was kept as $87 \mathrm{mM}$. The selectivity of the sensing system toward cyanide $\left(\mathrm{CN}^{-}\right)$was also evaluated by using another anions including $\mathrm{F}^{-}, \mathrm{Br}^{-}, \mathrm{Cl}^{-}, \mathrm{NO}_{3}{ }^{-}, \mathrm{CH}_{3} \mathrm{COO}{ }^{-}, \mathrm{H}_{2} \mathrm{PO}_{4}^{-}, \mathrm{SO}_{4}{ }^{2-}$, $\mathrm{CO}_{3}{ }^{2-}, \mathrm{N}_{3}{ }^{-}$. The salt solutions were prepared in distilled water and the concentration was kept as $10 \mathrm{ppm}$.

\subsection{Visual detection of cyanide in solid state}

The common filter paper was cropped in a size of a $1 \mathrm{~cm}$. Each spot was dyed by $10 \mathrm{~mL}$ of $87 \mu \mathrm{M} \mathrm{EuD}_{4} \mathrm{TEA}$ solution. When the fluorescent spots were completely dried, each surface was impregnated by $5 \mathrm{~mL}$ of Au NPs solution. Au NPS impregnated $\mathrm{EuD}_{4}$ TEA dye doped paper spot was finally treated with different concentrations of cyanide solution.The test stripes were designed as three spots: reference 1 (R1) sample (S) and reference 2 (R2). R1 and R2 utilized as control spots. The readout system consists of a commercial digital camera of smart phone with $1 / 2.5^{\prime \prime}$ CCD sensor and lens with focal length of $30 \mathrm{~mm}$ and $\mathrm{f} / 2.8$. UV illuminated test strips are placed perpendicular to the camera at a fixed distance of $8 \mathrm{~cm}$. (length of the apparatus). The test strip is uniformly illuminated with UV led (365 nm), to improve measurement accuracy and minimize the potential errors, the readout platform is made of black cardboard to provide complete isolation from any light reflection from hardware accessories and diffusers. In order to prevent artificial color changes, white balance and EV compensation properties of the camera were disabled.

\subsection{Image processing}

The home-made algorithm (MathCAD ${ }^{\circledR}$ ) used to retrieve the color component values. This analysis digitizes actual red color and in user-defined region of interests (ROIs). The algorithm converts the raw image (DNG file) to tagged image file format (TIFF) to extract red channel pixel intensities and compute averaging function to extent global value for whole image (no further background corrections were utilized).

\section{Results and discussions}

\subsection{Optical properties of $E u D_{4} T E A$ in solution}

The optical properties of $\mathrm{EuD}_{4}$ TEA in solution have been characterized, prior to explore sensing capability at solid state. Fig. 1a shows fluorescence spectrum of $\mathrm{EuD}_{4}$ TEA that exhibits strong fluorescence signal centered at $614 \mathrm{~nm}$ that is assigned to the ${ }^{5} \mathrm{D}_{0}$ to ${ }^{7} \mathrm{~F}_{2}$ transition. The emission peak with a broad tail around $625 \mathrm{~nm}$ is typical when Eu coordinated with unsaturated ligands. Upon mixing of equimolar $\mathrm{EuD}_{4} \mathrm{TEA}$ and $\mathrm{KCN}$ solutions, emission intensity of $\mathrm{EuD}_{4} \mathrm{TEA}$ has increased nearly three folds. Fluorescence titration experiments shown in Fig. $1 \mathrm{~b}$ depicts the response of $\mathrm{EuD}_{4} \mathrm{TEA}$ against the common anions $\mathrm{F}^{-}, \mathrm{N}_{3}^{-}, \mathrm{H}_{2} \mathrm{PO}_{4}^{-}, \mathrm{CH}_{3} \mathrm{COO}^{-}, \mathrm{Cl}^{-}, \mathrm{Br}^{-}$, $\mathrm{SO}_{4}{ }^{2-}, \mathrm{NO}_{3}{ }^{-}, \mathrm{CO}_{3}{ }^{2}$ to confirm the cyanide specific enhancement. The fluorescence intensity of $\mathrm{EuD}_{4} \mathrm{TEA}$ changed marginally as anion concentrations gradually increased, unlike $\mathrm{CN}^{-}$addition causes $80 \%$ enhancement in fluorescence intensity. The cyanide specific enhancement can be attributed to substitution reaction of $\mathrm{CN}^{-}$ by trimethyamine group in $\mathrm{EuD}_{4} \mathrm{TEA}$ thereby altering resonance structure of tetrakis dibenzoylmethide attached to Eu center. As a 
a)

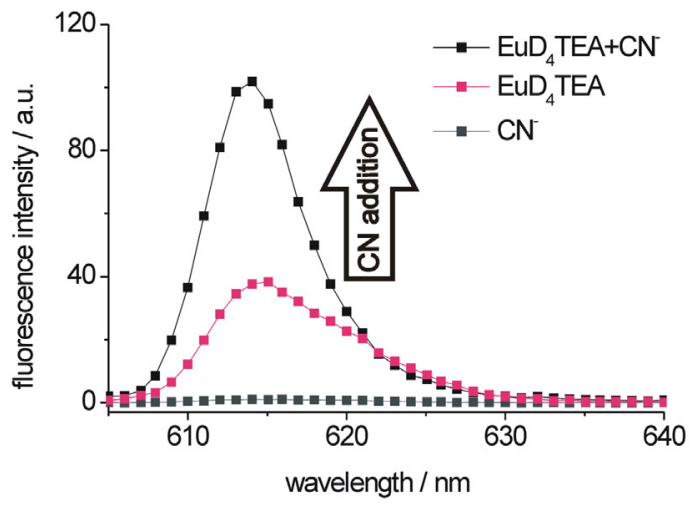

b)

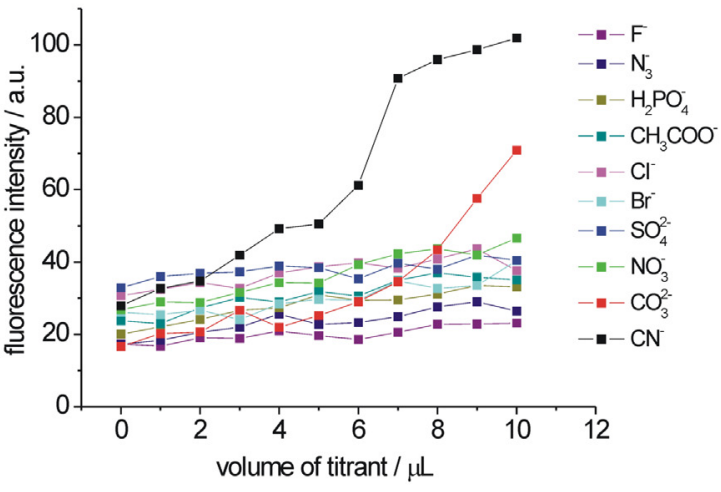

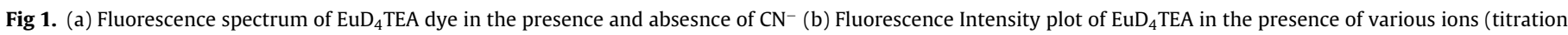
performed from 1 microliter to 10 microliter of ions).

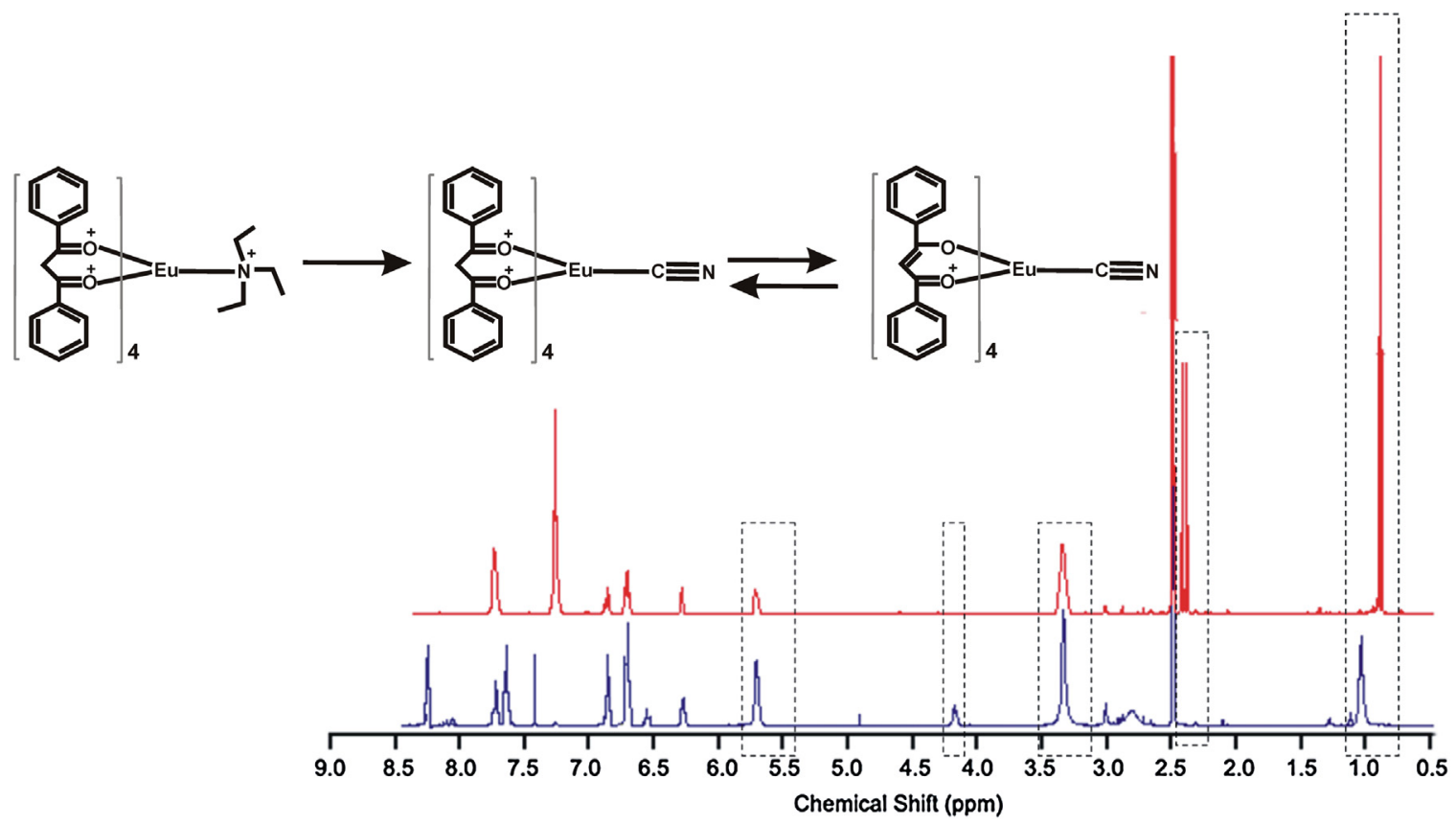

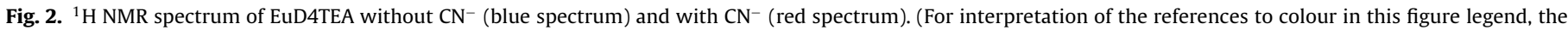
reader is referred to the web version of this article.)

result of substitution reaction, significant change in chemical vicinity of Eu and increase in charge density around coordination sphere occurs that facilitates electronic transitions. To support the idea of substitution reaction, NMR experiments have been performed. The NMR spectra of two solutions $\mathrm{EuD}_{4} \mathrm{TEA}$ (blue curves) and $\mathrm{EuD}_{4} \mathrm{CN}$ (red curve) were shown in Fig. 2. The protons of triethylamine in EuD 4 TEA complex shows broad signals at 2.81 and $1.05 \mathrm{ppm}$. After treatment with cyanide ion, triethylamine protons gave first order NMR signals at 2.39 and $0.90 \mathrm{ppm}$ for $\mathrm{CH}_{2}$ and $\mathrm{CH}_{3}$ groups respectively and such change was interpreted as the detachment of triethylamine from $\mathrm{EuD}_{4}$ TEA complex. The NMR spectrum has also revealed that equilibrium exists between keto and enol forms of 1,3-dicarbonyl compounds as shown in schematic in Fig. 2. Equilibrium became clearer by the peaks at 5.65 and $4.14 \mathrm{ppm}$ belongs to $=\mathrm{CH}$ of the enol form and methylene group in the keto form respectively. The integrals of these peaks indicate that the ratio of the enol form to keto is 5:1 in the complex. Treatment of EuD $\mathrm{E}_{4} \mathrm{TEA}$ with cyanide ion causes the loss of methylene signal in ${ }^{1} \mathrm{H}$ NMR at $4.14 \mathrm{ppm}$ and implies that equilibrium completely shifts to the enol form. Chemical shifts of the aromatic protons are at 7.65 and $7.19 \mathrm{ppm}$ also show the formation of chemically equivalent enol form. This result prove that chemical environment of Eu atom has drastically changed by $\mathrm{CN}^{-}$due to substitution reaction.

\subsection{Optical properties at solid state}

In Fig. 3a the top row shows EuD 4 TEA, rhodamine B (Rho-B), rhodamine 6G (Rho-6G) fluorescein hydrazide (Fluo-Hyd) impregnated paper substrates under UV illumination. These substrates exhibit characteristic luminescent colors of impregnated dyes. As paper substrate were aged for two weeks under ambient conditions, the luminescent color of all substrate changed substantially unlike $\mathrm{EuD}_{4}$ TEA (see the second row). The Fig. 3b shows that the percent change in RGB values which were calculated by proportioning of final $R_{\text {fin }} G_{f i n} B_{\text {fin }}$ values (bottom image) to initial $R_{\text {in }} G_{\text {in }}$ $B_{\text {in }}$ (top image). The percent RGB change was found to be over $10 \%$ and $20 \%$ in red and blue components respectively for Rho-B and 
a)

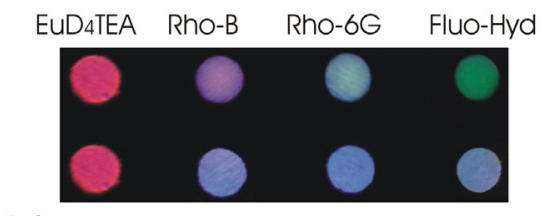

b)

d)

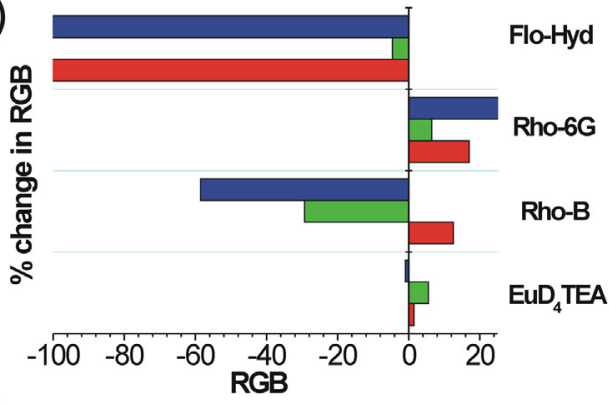

c)

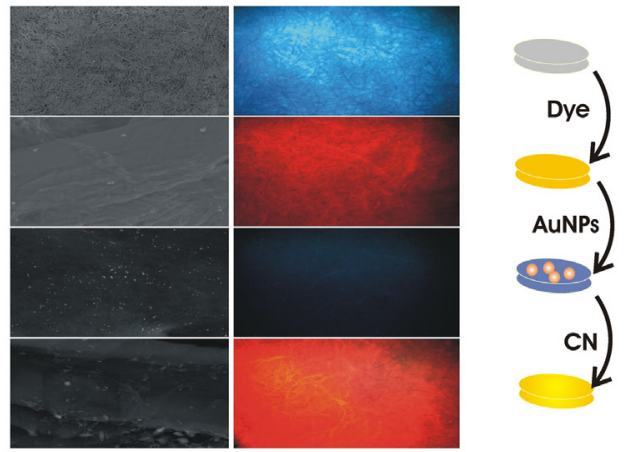

e)

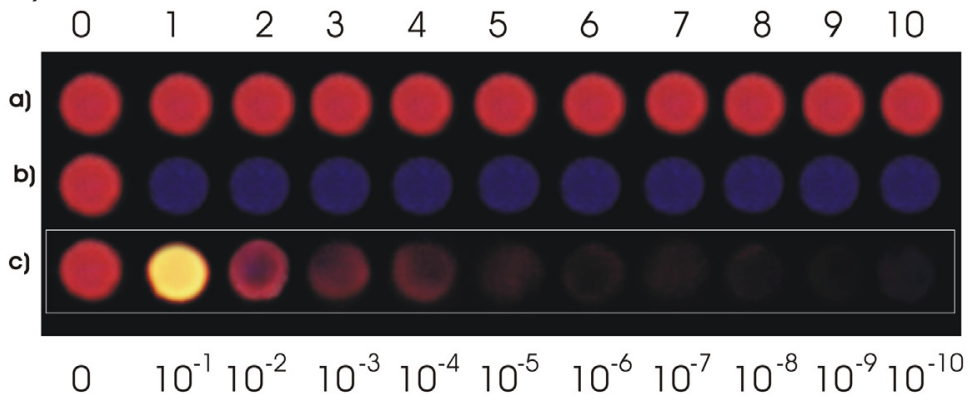

[CN] concentration

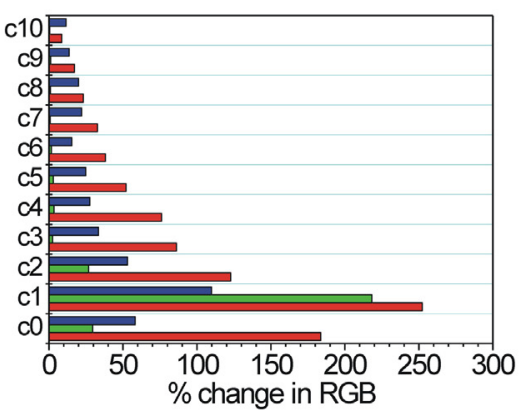

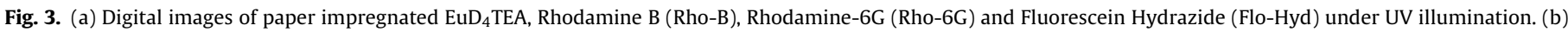

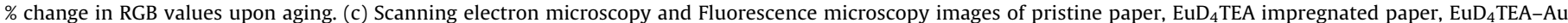

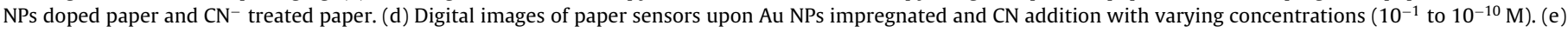

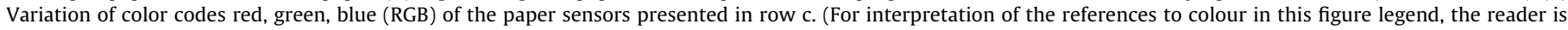
referred to the web version of this article.)

Rho-6G referring to moderate color change by ageing. The FluoHyd impregnated substrates exhibited the most substantial loss (over $100 \%$ change in red and blue components) shows incapability of preserving optical property at solid substrate. $\mathrm{EuD}_{4}$ TEA exhibit marginal change less than $5 \%$ in RBG upon ageing. This results prove that EuD 4 TEA has long period of durability of luminescence at solid substrate. The durability of $\mathrm{EuD}_{4}$ TEA on solid support becomes major advantage over common fluorescent probes. However fluorescent enhancement by cyanide provides enough contrast only at high concentration range $\left(>10^{-4} \mathrm{M}\right)$ and does not helpful for monitoring at critical concentration range such as $10^{-6} \mathrm{M}$. Here we hypothesized that utilization of gold nanoparticles (AuNPs) is useful to develop the response and enable visual detection of $\mathrm{CN}^{-}$. The strategy relies on complete fluorescence quenching of EuD4TEA impregnated paper by controlled deposition of AuNPs and dissolution of AuNPs by cyanide that causing fluorescence recovery and enhancement. Fig. 3c (right panel) shows fluorescence microscopy images of pristine paper, and $\mathrm{EuD}_{4} \mathrm{TEA}$ impregnated paper substrate, after addition of AuNPs and $\mathrm{CN}^{-}$respectively. As seen in top image pristine paper exhibits no luminescence whereas EuD $\mathrm{D}_{4} \mathrm{TEA}$ impregnation causes bright orange luminescence. By addition Au NPs total quenching occurs due to energy transfer from EuD 4 TEA to Au NPs. Upon $\mathrm{CN}^{-}$addition orange luminescence were recovered due to complete dissolution of AuNPs. The left panel of Fig. $3 \mathrm{c}$ shows SEM images of corresponding steps shown in right panel. The top SEM image shows the fibrous structure of pristine paper and it has changed to smoother morphology by $\mathrm{EuD}_{4} \mathrm{TEA}$ impregnation (sec- ond image). SEM imaging reveals that spherical Au NPs particles were dispersed on paper and has dissolved after $\mathrm{CN}^{-}$addition. This results show that our proposed strategy of cyanide detection by dye-nanoparticle impregnated paper platform is valid.

The control of concentration of AuNPs on the EuD 4 TEA impregnated paper substrate is critical for reproducible color development therefore AuNPs deposition has been standardized. AuNPs solution with an optical density of 0.1 was used for deposition on to $\mathrm{EuD}_{4} \mathrm{TEA}$ impregnated paper that were applied till complete wetting. Fig. 3d shows the digital images of paper substrates: row 1 is $\mathrm{EuD}_{4}$ TEA impregnated paper which is fluorescent, row 2 is AuNPs modified EuD ${ }_{4}$ TEA impregnated paper (quenched). The third row shows color development of AuNPs modified $\mathrm{EuD}_{4} \mathrm{TEA}$ impregnated paper to varying concentrations of $\mathrm{CN}^{-}\left(10^{-1}-10^{-10} \mathrm{M}\right)$. As shown in Fig. 3d spots were in row 1 exhibit no significant variations in color as well as intensities. The corresponding color code analysis in Fig. 3e confirms the variations in colors (2\%) from spot a to $g$ in row1 is marginal. This assures impregnation of EuD ${ }_{4}$ TEA homogenously distributed on paper surface. The complete quenching in luminescence has been observed in row-2 by applying the nanoparticles suggesting AuNPs were allocated to the vicinity of dye molecules after deposition. Color code analysis shows that nearly $1 \%$ variations exist among different spots in row-2, implying deposition step is reproducible. Upon $\mathrm{CN}^{-}$addition with varying concentration on to paper sensors, concentration dependent color development has occurred. The color code analysis of row-3 reveals two major features; both luminescence and color development occurs depending 


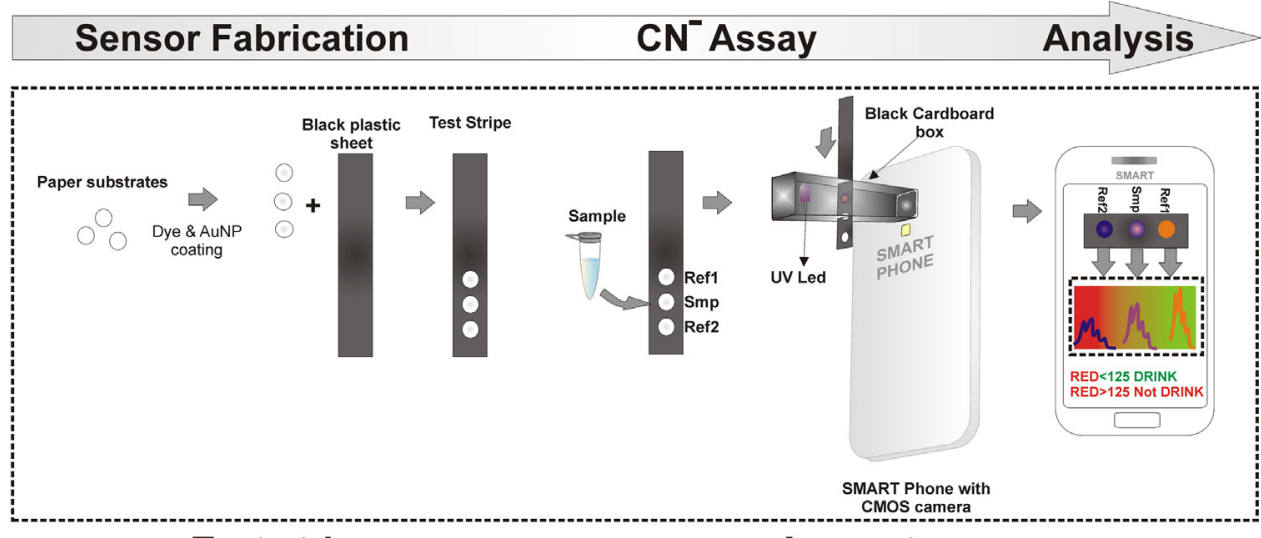

Test stripe

Apparatus

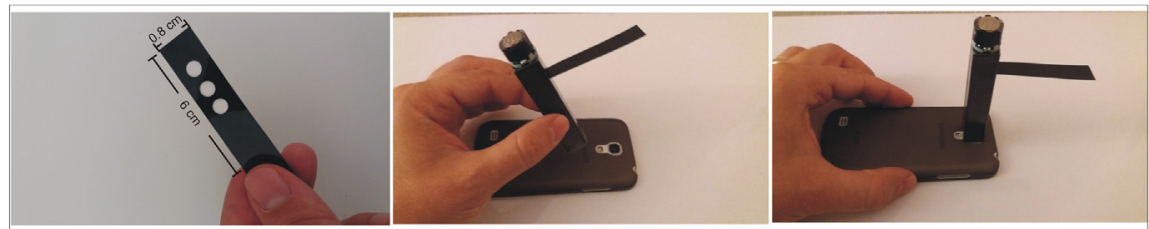

Scheme1. The fabrication steps of $\mathrm{EuD}_{4}$ TEA-Au NPs doped paper based sensor, proposed CN- detection assay and analysis methodology.

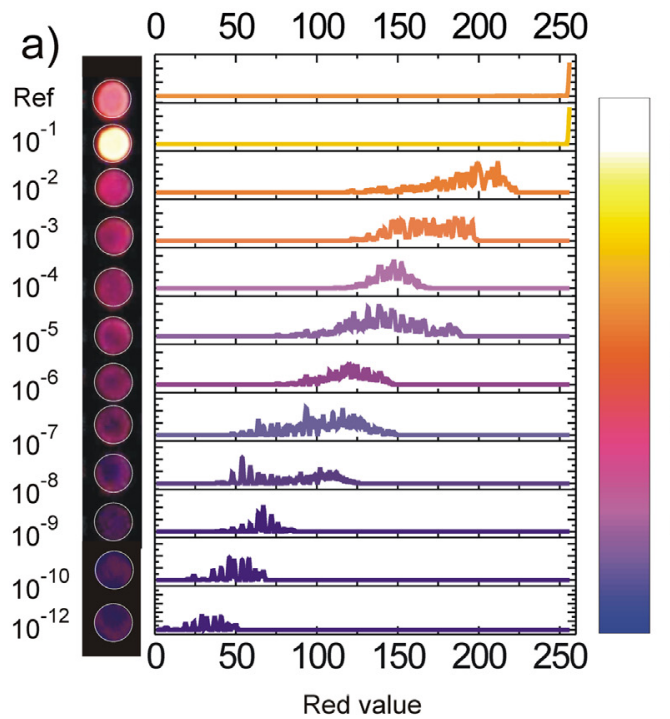

b)

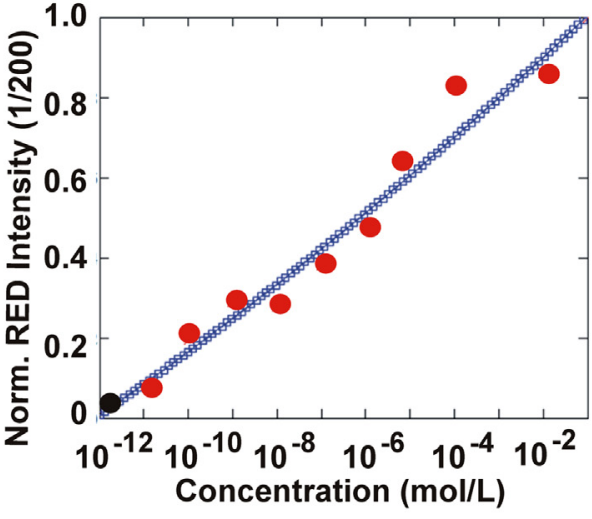

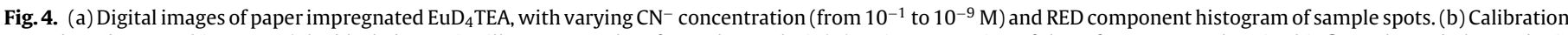

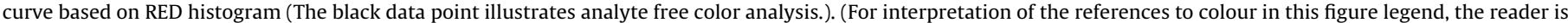
referred to the web version of this article.)

on $\mathrm{CN}^{-}$concentration increases. The basic mechanism of color development is based on dissolution of AuNPs/fluorescence turn on and $\mathrm{CN}^{-}$specific enhancement. To perform quantitative analysis, images were imported to image processing software to yield color codes red, green, blue (RGB). The "red component" exhibit linear correlation by the cyanide concentration. It was exhibited in Fig. 3e as cyanide concentration changes from $10^{-1}$ to $10^{-10} \mathrm{M}$ in solution red component decreases $\sim 250$ to $\sim 20$. This linear dependency is used later to calibrate color component of corresponding images to the precise quantification of analyte concentration.

\subsection{Assay development and color based quantification of cyanide by smart phone}

The Scheme 1 shows steps for fabrication of paper based sensor, instrument free cyanide detection assay and quantitative analysis by simple image processing. The apparatus cell shown in Scheme 1 is made of black cardboard equipped with UV-Led source fitted into smart phone camera, has been used. The three spots; reference 1 (R1) sample (S) and reference 2 (R2) were utilized to perform cyanide assay. At first step, R1 (EuD 4 TEA impregnated, fluorescent state) S and R2 (EuD 4 TEA -AuNPs doped, quenched state) paper spots were fixed on to black plastic sheets. Then the color of R1 and R2 were recorded to calibrate quenched and fluorescent state. Finally, color development at $\mathrm{S}$ spot (middle spot) were recorded to analyze presence of $\mathrm{CN}^{-}$. The quantitative analysis of $\mathrm{CN}^{-}$were computed by image processing relying on color code calibrated algorithm as well as home-made smart phone application. Detection mechanism relying on two effects (i) dissolution of gold nanoparticles that causes fluorescence recovery and (ii) ligand exchange of triethyl amine with $\mathrm{CN}$ group stimulating cyanide specific fluorescence enhancement. The promising response of paper 
Table 1

Comparison of recent sensing methodologies of cyanide.

\begin{tabular}{|c|c|c|c|c|}
\hline No & Technique & Sensing element & Comments & Refs. \\
\hline 1 & Naked-Eye & $\begin{array}{l}\text { europium tetrakis dibenzoylmethide } \\
\text { triethylammonium }\end{array}$ & $\begin{array}{l}\text { advantage: suitable for naked eye detection of cyanide in } \\
\text { water, excellent limit of detection }\left(10^{-12} \mathrm{M}\right) \text {, off field detection } \\
\text { methodology, no lab facility requirement. } \\
\text { disadvantage: not useful for colored or crude samples }\end{array}$ & Present work \\
\hline 2 & UV-vis spectra & acylhydrazone unit & $\begin{array}{l}\text { advantage: suitable naked eye detection of cyanide in water } \\
\text { disadvantage: limit of detection }(6,5 \mu \mathrm{M}) \text { is slightly higher } \\
\text { than allowed dose, not suitable for water safety control, } \\
\text { instrument and lab facility required }\end{array}$ & [7] \\
\hline 3 & UV-vis spectra & $\begin{array}{l}\text { gluco-conjugated } o \text {-(carboxamido) } \\
\text { aldehyde hydrazone }\end{array}$ & $\begin{array}{l}\text { advantage: selective detection of cyanide in the presence of } \\
\text { interfering common ions in water } \\
\text { disadvantage: instrument and lab facility required, not } \\
\text { applicable to solid substrate or test stripe }\end{array}$ & {$[8]$} \\
\hline 4 & UV-vis spectra & $\begin{array}{l}\text { 4,4'-bis-[3-(4-nitrophenyl) thiourea] } \\
\text { diphenyl methane (or ether }\end{array}$ & $\begin{array}{l}\text { advantage: significant color transition, quick response time, } \\
\text { naked eye detection } \\
\text { disadvantage: limit of detection is not suitable for water } \\
\text { safety control }\end{array}$ & [9] \\
\hline 4 & $\begin{array}{l}\text { UV-vis spectra, } \\
\text { Fluorescence spectra, }\end{array}$ & $\begin{array}{l}\text { coumarin and a malonyl urea } \\
\text { derivatives dyes }\end{array}$ & $\begin{array}{l}\text { advantage: low limit of detection ( } \mathrm{nM} \text { ), dual detection (UV-vis } \\
\text { spectra, Fluorescence spectra) } \\
\text { disadvantage: instrument and lab facility required }\end{array}$ & [10] \\
\hline 5 & $\begin{array}{l}\text { UV-vis spectra, } \\
\text { Fluorescence spectra, }\end{array}$ & $\begin{array}{l}\text { aggregation-induced emissive } \\
\text { hexaphenylbenzene }\end{array}$ & $\begin{array}{l}\text { advantage: Low limit of detection }\left(\mathrm{ng} / \mathrm{cm}^{2}\right) \text {, dual detection } \\
\text { (UV-vis spectra, Fluorescence spectra) } \\
\text { disadvantage: solvent mixture (HEPES/TFA/EtOH) is required } \\
\text { for detection, lab facility required, tedious synthesis protocol }\end{array}$ & [11] \\
\hline 6 & $\begin{array}{l}\text { UV-vis spectra, electrical } \\
\text { response }\end{array}$ & 7,7,8,8-tetracyanoquinodimethane & $\begin{array}{l}\text { advantage: suitable naked eye detection of cyanide. Both } \\
\text { optical and electrical detection is possible } \\
\text { disadvantage: solvent mixture (water/MeCN) is required, lab } \\
\text { facility required. }\end{array}$ & [12] \\
\hline 7 & $\begin{array}{l}\text { UV-vis spectra, } \\
\text { Fluorescence spectra, }\end{array}$ & 5,10-dihexyl-5,10-dihydrophenazine & $\begin{array}{l}\text { advantage: suitable naked eye detection of cyanide. Low limit } \\
\text { of detection }\left(5.8 \times 10^{-8} \mathrm{M}\right) \\
\text { disadvantage: Solvent mixture } \mathrm{MeCN} / \text { water is required, } \\
\text { tedious synthesis protocol. }\end{array}$ & [13] \\
\hline
\end{tabular}

sensors were translated to a naked-eye $\mathrm{CN}^{-}$detection assay that are based on colorimetric analysis by a smart phone. The colorimetric analysis were conducted by homemade algorithm (MathCAD ${ }^{\circledR}$ ) determines the red component values from the test zone. The white circular region of interests (ROIs) shown in Fig. 4a were set to define the scan area $(\sim 0.5 \mathrm{~cm}$ in diameters) prior to initialization of analysis. The algorithm first converts the raw image (DNG file) to tagged image file format (TIFF) to extract the red channel pixel intensities. Then it averages the red intensity " $R_{i}$ " of each pixels by proportioning to the total number of pixels in defined ROI ( $\sum$ $\mathrm{R}_{\mathrm{i}}$ /no.of pixels, typical resolution of $2112 \times 2816$ pixels). Fig. $4 a$ shows the distribution of red values over the ROI for the paper substrate treated by varying concentration of $\mathrm{CN}^{-}$for example paper substrate treated with $10^{-9} \mathrm{M} \mathrm{CN}^{-}$exhibit red component distribution around 50-75 with a maximum at $\sim 60$. As $\mathrm{CN}^{-}$concentration increased the max intensity in distribution of red values shift to the 200. It is observed that one order of magnitude change in $\mathrm{CN}^{-}$concentration from $10^{-9} \mathrm{M}$ to $10^{-8} \mathrm{M}$ causes shift in red value maximum from $\sim 60$ to $\sim 110$ (see Fig. $4 a$ ). The similar trend also observed for other concentrations between $10^{-7} \mathrm{M}$ to $10^{-2} \mathrm{M}$ and causing a gradual increase in red value maximum shifts from 125 to 200. This promising correlation have been exploited to obtain calibration curve relying on the shift of red value maximum by concentration. The Fig. $4 \mathrm{~b}$ shows linear dependency between varying concentrations of $\mathrm{CN}^{-}\left(10^{-12} \mathrm{M}\right.$ to $\left.10^{-2} \mathrm{M}\right)$ and normalized red intensity that have been utilized as calibration curve. The artesian well sample was selected as unknown and tested to validate quantification capability of proposed methodology. Fig. 5a shows the color development of six paper substrates from unknown sample (without pretreatment) and its dilution set that were prepared consecutive dilution of unknown sample. The "S" spot in row-1 is the unknown sample that exhibits significant color difference between spots $\mathrm{R} 1$ and $\mathrm{R} 2$ indicating the presence of $\mathrm{CN}^{-}$. For the diluted samples at the rows from 2 to 6 , color differences between R1 and S spots gradually converges referring to dilution dependent concen-

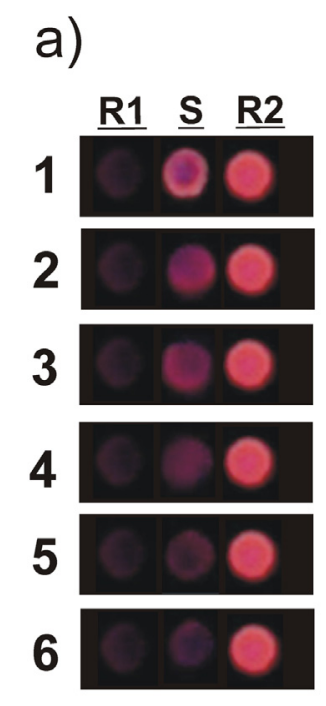

b)

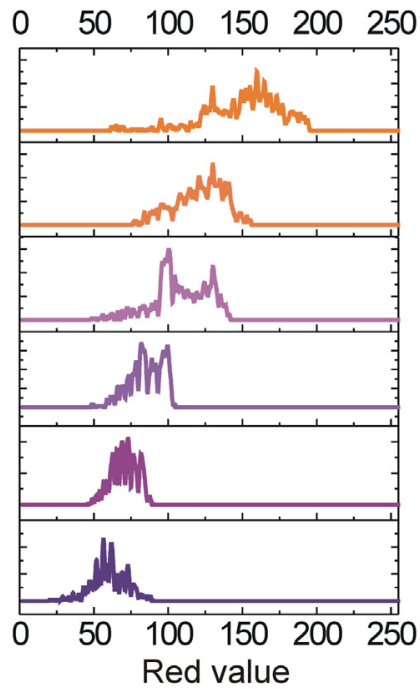

Fig. 5. (a) Digital images of test stripes utilized for detection of unknown concentration of $\mathrm{CN}^{-}$. (b) RED component histogram of sample spots. (For interpretation of the references to colour in this figure legend, the reader is referred to the web version of this article.)

tration gradient in cyanide. These images were analyzed by above mentioned algorithm to quantify $\mathrm{CN}^{-}$concentrations in unknown sample and its dilution set. As shown in Fig. $5 \mathrm{~b}$ paper substrates 1-6 exhibit distribution in red value between 160-60 that corresponds to $\mathrm{CN}^{-}$concentration variation between $5.0 \times 10^{-5} \mathrm{M}$ and $6.5 \times 10^{-10} \mathrm{M}$ respectively. The chromatographic detection has performed for unknown sample confirming cyanide concentration as $4.4 \times 10^{-5} \mathrm{M}$ that refers to $12 \%$ absolute deviation between proposed methodology and conventional methodology $[43,44]$. 


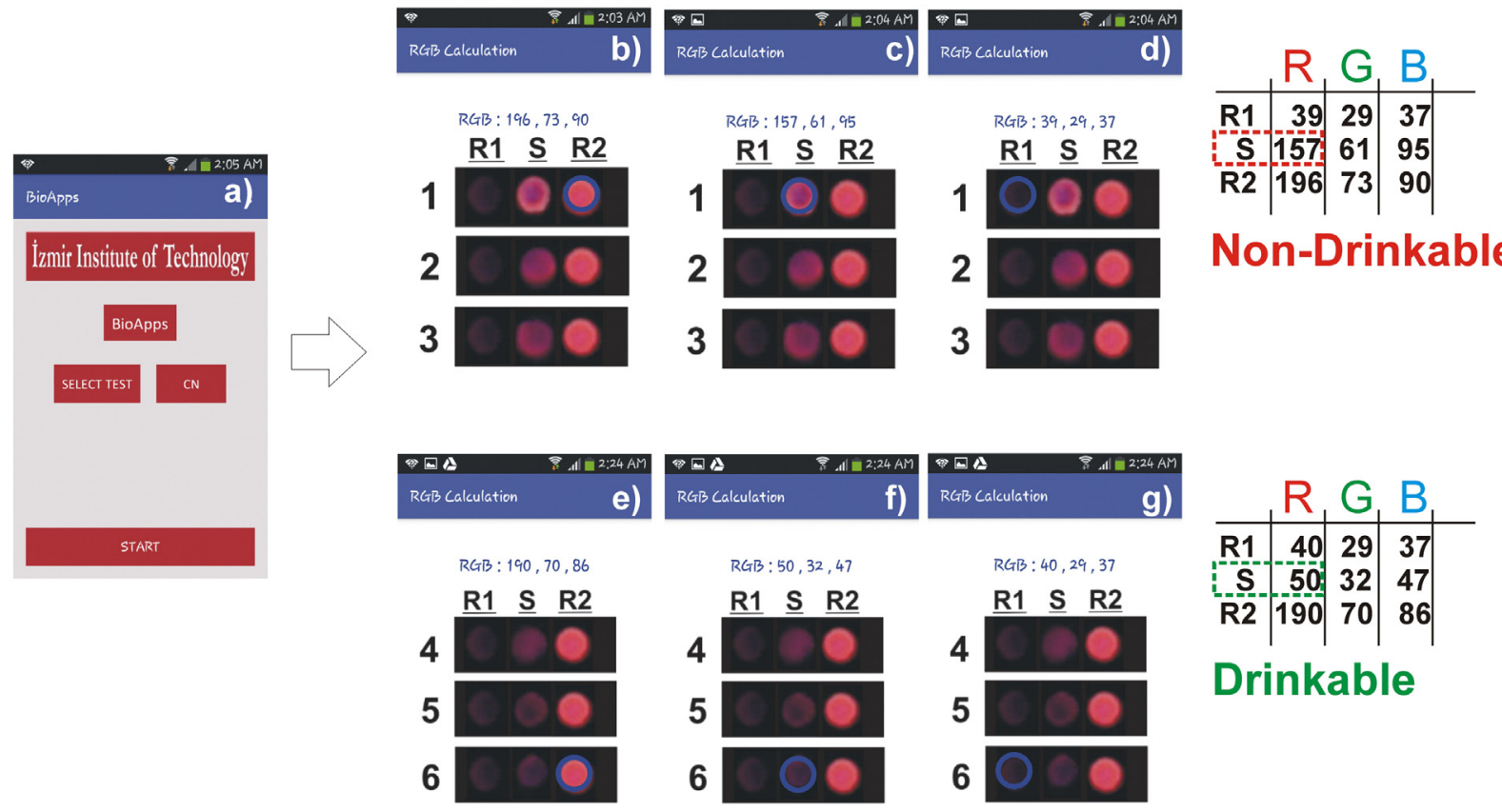

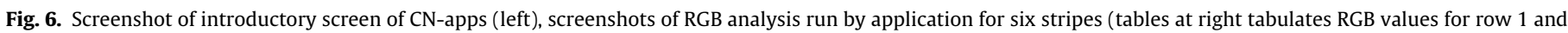
row 6.).

We have taken further step to develop easy-to-use mobile phone application that analyses the color code intensities to detect $\mathrm{CN}^{-}$in drinking water. In a typical mobile detection operation, described assay protocol has been followed and color development on spots analyzed by mobile application. This simple application is an algorithm compatible to android operating system that helps to determine the color component of image of spots. The Fig. 6 shows screen shots of mobile application computed to deduce red component intensities (see the tables for all RGB values). At row 1 red intensity of S spot has deduced as 157 (non-drinkable) while at row 6 , it is 50 (drinkable). The analysis by mobile application ascertains differentiation of drinkable and non-drinkable water by providing quick detection of lethal dose of $\mathrm{CN}^{-}$in drinking water. The Table 1 summarizes major advantages of present work over earlier methods. The short detection time, no requirement to laboratory facilities and no pretreatment for samples make our method useful for detection in field. Since the proposed method relies on color change, clear samples are required that limiting the use for detection of colored and crude samples. However simple filtration process often utilized water clearing is potentially applicable to overcome interferences.

\section{Conclusion}

In summary, a new fluorescence turn on cyanide detection assay employs disposable paper based sensing platform has been demonstrated. The proposed methodology describes facilitation of quantitative detection of $\mathrm{CN}^{-}$by custom-made image processing algorithm to standardize the detection methodology which recognize color codes providing $\mathrm{CN}$ detection as low as $10^{-12} \mathrm{M}$. The new algorithm is applicable to ordinary smart phone equipped with camera and transforms these devices into a quantitative cyanide detector.

\section{References}

[1] C. Young, L. Tidwell, C. Anderson, Social Industrial and Economic Aspects, Minerals, Metals, and Materials Society, Warrendale, 2001.
[2] K.W. Kulig, Cyanide Toxicity, U.S. Department of Healthand Human Services, Atlanta, 1991

[3] S.I. Baskin, T.G. Brewer, F. Sidell, E.T. Takafuji, D.R. Franz (Eds.), Medical Aspects of Chemical and Biological Warfare, TMM publications, Washington, 1997, p. 271

[4] (a) Guidelines for Drinking Water Quality, World Health Organization, Geneva, 1996:

(b) G.D. Muir, Hazards in Chemical Laboratory, The Royal Chemical Society, London, 1977.

[5] (a) Z. Xu, X. Chen, H.N. Kim, J. Yoon, Sensors for the optical detection of cyanide ion, Chem. Soc. Rev. 39 (2010) 127-137;

(b) E.P. Randviir, C.E. Banks, The latest developments in quantifying cyanide and hydrogen cyanide, Trends Anal. Chem. 64 (2015) 75-85.

[6] F. Wang, L. Wang, X. Chen, J. Yoon, Recent progress in the development of fluorometric and colorimetric chemosensors for detection of cyanide ions, Chem. Soc. Rev. 43 (2014) 4312-4324.

[7] D. Zha, L. You, Multiresponsive dynamic covalent assemblies for the selective sensing of both $\mathrm{Cu}^{2+}$ and $\mathrm{CN}^{-}$in water, ACS Appl. Mater. Interfaces 8 (2016) 2399-2405.

[8] J. Isaad, A. El Achari, A novel glucocojugated N-acetylamino aldehyde hydrazone azo dye as chromogenic probe for cyanide detection in water, Anal. Chim. Acta 694 (2011) 120-127.

[9] V. Kumar, M.P. Kaushik, A.K. Srivastava, A. Pratap, V. Thiruvenkatam, T.N.G. Row, Thiourea based novel chromogenic sensor for selective detection of fluoride and cyanide anions in organic and aqueous media, Anal. Chim. Acta 663 (2010) 77-84

[10] H. Li, T. Chen, L. Jin, Y. Kan, B. Yin, Colorimetric and fluorometric dual-modal probes for cyanide detection based on the doubly activated Michael acceptor and their bioimaging applications, Anal. Chim. Acta 852 (2014) 203-211.

[11] S. Pramanik, V. Bhalla, M. Kumar, Hexaphenylbenzene-based fluorescent aggregates for ratiometric detection of cyanide ions at nanomolar level: set-reset memorized sequential logic device, ACS Appl. Mater. Interfaces 6 (2014) 5930-5939.

[12] M.R. Ajayakumar, K. Mandal, K. Rawat, D. Asthana, R. Pandey, A. Sharma, S. Yadav, S. Ghosh, P. Mukhopadhyay, Single electron transfer-driven multi-dimensional signal read-out function of TCNQ as an off-the-shelf detector for cyanide, ACS Appl. Mater. Interfaces 5 (2013) 6996-7000.

[13] L. Yang, X. Li, J. Yang, Y. Qu, J. Hua, Colorimetric and ratiometric near-Infrared fluorescent cyanide chemodosimeter based on phenazine derivatives, ACS Appl. Mater. Interfaces 5 (2013) 1317-1326.

[14] X. Cheng, R. Tang, H. Jia, J. Feng, J. Qin, Z. Li, New fluorescent and colorimetric probe for cyanide: direct reactivity, high selectivity, and bioimaging application, ACS Appl. Mater. Interfaces 4 (2012) 4387-4392.

[15] C. Maennel-Croise, F. Zelder, Complex samples cyanide detection with immobilized corrinoids, ACS Appl. Mater. Interfaces 4 (2012) 725-729.

[16] J. Rull-Barrull, M. d'Halluin, E. Le Grognec, F.X. Felpin, Chemically-modified cellulose paper as smart sensor device for colorimetric and optical detection of hydrogen sulfate in water, Chem. Commun. 52 (2016) 2525-2528.

[17] Y. Shiraishi, S. Sumiya, K. Manabe, T. Hirai, Thermoresponsive copolymer containing a coumarin-spiropyran conjugate: reusable fluorescent sensor for 
cyanide anion detection in water, ACS Appl. Mater. Interfaces 3 (2011) 4649-4656

[18] S.C. Wei, P.H. Hsu, Y.F. Lee, Y.W. Lin, C.C. Huang, Selective detection of iodide and cyanide anions using gold-nanoparticle-based fluorescent probes, ACS Appl. Mater. Interfaces 4 (2012) 2652-2658.

[19] W.-C. Lin, J.-W. Hu, K.-Y. Chen, A ratiometric chemodosimeter for highly selective naked-eye and fluorogenic detection of cyanide, Anal. Chim. Acta 893 (2015) 91-100.

[20] L.D. Chen, X.U. Zou, P. Buehlmann, Cyanide-selective electrode based on Zn(II) tetraphenylporphyrin as ionophore, Anal. Chem. 84 (2012) 9192-9198.

[21] R. Jackson, R.P. Oda, R.K. Bhandari, S.B. Mahon, M. Brenner, G.A. Rockwood, B.A. Logue, Development of a fluorescence-based sensor for rapid diagnosis of cyanide exposure, Anal. Chem. 86 (2014) 1845-1852.

[22] K.H. Jung, K.H. Lee, Efficient ensemble system based on the copper binding motif for highly sensitive and selective detection of cyanide ions in $100 \%$ aqueous solutions by fluorescent and colorimetric changes, Anal. Chem. 87 (2015) 9308-9314.

[23] X. Lou, L. Qiang, J. Qin, Z. Li, A new rhodamine-based colorimetric cyanide chemosensor: convenient detecting procedure and high sensitivity and selectivity, ACS Appl. Mater. Interfaces 1 (2009) 2529-2535.

[24] C. Maennel-Croise, B. Probst, F. Zelder, A straightforward method for the colorimetric detection of endogenous biological cyanide, Anal. Chem. 81 (2009) 9493-9498.

[25] P.C.A. Swamy, S. Mukherjee, P. Thilagar, Dual binding site assisted chromogenic and fluorogenic recognition and discrimination of fluoride and cyanide by a peripherally borylated metalloporphyrin: overcoming anion interference in organoboron based sensors, Anal. Chem. 86 (2014) 3616-3624

[26] C.H. Zong, L.R. Zheng, W.H. He, X.Y. Ren, C.H. Jiang, L.H. Lu, In situ formation of phosphorescent molecular Gold(I) cluster in a macroporous polymer film to achieve colorimetric cyanide sensing, Anal. Chem. 86 (2014) 1687-1692.

[27] E. Carrilho, A.W. Martinez, G.M. Whitesides, Understanding wax printing: a simple micropatterning process for paper-based microfluidics, Anal. Chem. 81 (2009) 7091-7095.

[28] C.M. Cheng, A.W. Martinez, J. Gong, C.R. Mace, S.T. Phillips, E. Carrilho, K.A. Mirica, G.M. Whitesides, Paper-based ELISA, Angew. Chem. Int. Ed. 49 (2010) 4771-4774.

[29] J.L. Delaney, C.F. Hogan, J.F. Tian, W. Shen, Electrogenerated chemiluminescence detection in paper-based microfluidic sensors, Anal. Chem. 83 (2011) 1300-1306.

[30] A. Alvarez-Diaz, A. Salinas-Castillo, M. Camprubi-Robles, J.M. Costa-Fernandez, R. Pereiro, R. Mallavia, A. Sanz-Medel, Conjugated polymer microspheres for turn-off/turn-on fluorescence optosensing of inorganic ions in aqueous media, Anal. Chem. 83 (2011) 2712-2718.

[31] B. Kannan, S. Jahanshahi-Anbuhi, R.H. Pelton, Y.F. Li, C.D.M. Filipe, J.D. Brennan, Printed paper sensors for serum lactate dehydrogenase using pullulan-based inks to immobilize reagents, Anal. Chem. 87 (2015) 9288-9293.

[32] L.Z. Li, X.L. Huang, W. Liu, W. Shen, Control performance of paper-based blood analysis devices through paper structure design, ACS Appl. Mater. Interfaces 6 (2014) 21624-21631.

[33] Y.H. Zhu, X.W. Xu, N.D. Brault, A.J. Keefe, X. Han, Y. Deng, J.Q. Xu, Q.M. Yu, S.Y. Jiang, Cellulose paper sensors modified with zwitterionic poly(carboxybetaine) for sensing and detection in complex media, Anal. Chem. 86 (2014) 2871-2875.

[34] J.I. Hong, B.Y. Chang, Development of the smartphone-based colorimetry for multi-analyte sensing arrays, Lab Chip 14 (2014) 725-1732.
[35] J.R. Askim, K.S. Suslick, Hand-held reader for colorimetric sensor arrays, Anal. Chem. 87 (2015) 7810-7816.

[36] J.M. Azzarelli, K.A. Mirica, J.B. Ravnsbaek, T.M. Swager, Wireless gas detection with a smartphone via rf communication, Proc. Natl. Acad. Sci. U. S. A. 111 (2014) 18162-18166.

[37] B. Berg, B. Cortazar, D. Tseng, H. Ozkan, S. Feng, Q.S. Wei, R.Y.L. Chan, J Burbano, Q. Farooqui, M. Lewinski, D. Di Carlo, O.B. Garner, A. Ozcan, Cellphone-based hand-held microplate reader for point-of-care testing of enzyme-linked immunosorbent assays, ACS Nano 9 (2015) 7857-7866.

[38] J.C. Contreras-Naranjo, Q.S. Wei, A. Ozcan, Mobile phone-based microscopy, sensing, and diagnostics, IEEE J. Sel. Top. Quant. 22 (2016).

[39] O. Dalstein, D.R. Ceratti, C. Boissiere, D. Grosso, A. Cattoni, M. Faustini, Nanoimprinted, submicrometric, MOF-based 2D photonic structures: toward easy selective vapors sensing by a smartphone camera, Adv. Funct. Mater. 26 (2016) 81-90.

[40] X.W. Wang, Y. Qin, M.E. Meyerhoff, Paper-based plasticizer-free sodium ion-selective sensor with camera phone as a detector, Chem. Commun. 51 (2015) 15176-15179.

[41] R.S. Fontenot, W.A. Hollerman, K.N. Bhat, M.D. Aggarwal, Synthesis and characterization of highly triboluminescent doped europium tetrakis compounds, J. Lumin. 132 (2012) 1812-1818.

[42] J. Kimling, M. Maier, B. Okenve, H. Ballot, A. Plech, Turkevich method for gold nanoparticle synthesis revisited, J. Phys. Chem. B 110 (2006) 15700-15707.

[43] M.F. Cengiz, M.Z. Durak, S. Nilufer, A.K. Bilgin, Ion chromatographic determination of free cyanide in different classes of bottled natural mineral water consumed in Turkey, Int. J. Food Prop. 18 (2015) 746-756.

[44] I.F. Bolarinwa, C. Orfila, M.R.A. Morgan, Determination of amygdalin in apple seeds, fresh apples and processed apple juices, Food Chem. 170 (2015) 437-442.

\section{Biographies}

Anil İncel has received his master degree from İzmir Institute of Technology in 2016 and he started his PhD study at Biofilms Research Center for Biointerfaces, Department of Biomedical Sciences, Faculty of Health and Society, Malmö University.

Osman Akin is assistant professor at İzmir Katip Çelebi University. His research focus is fiber optic sensors and plasmonics.

Ali Çăgır is associated professor in İzmir Institute of Technology. His research activities are mainly focusing on medicinal chemistry and anti-cancer drugs.

Ümit Hakan Yıldız is assistant professor in İzmir Institute of Technology at Department of Chemistry. His research activities are polymer synthesis, fluorescent sensor, thin films and bio-interface. He is author and co-authors of over twenty journal articles.

Mustafa Demir is full professor and Chairman of Material Science and Engineering in İzmir Institute of Technology. Prof Demir's group activities are material synthesis, electrospinning, polymer and inorganic composites, polymer processing. He is author and co-authors of over fourth journal articles. 